\title{
The Second to Fourth Digit Ratio in Elite and Non-Elite Greco-Roman Wrestlers
}

\author{
by \\ Mohammad Keshavarz', Mahdi Bayati², Babak Farzad³, Amirbahador Dakhili1, \\ Hamid Agha-Alinejad ${ }^{1}$
}

\begin{abstract}
A low second-to-fourth digit ratio $(2 D: 4 D)$ has been reported to correlate with high performance and athletic potential of an individual in sport. It has been suggested that 2D:4D is a relatively weak predictor of strength and a stronger predictor of efficiency in aerobic exercise. Comparing extreme groups on a continuum of sports performance requiring high power (physical strength) output would be helpful to resolve this issue. Therefore, the purpose of the present study was to compare the 2D:4D ratio of world-class elite Greco-Roman wrestlers $(n=10)$ taking part in Olympic fitness camps in 2013 with the 2D:4D ratio of non-elite collegiate wrestlers $(n=20)$, and age-matched sedentary males $(n=40)$. The $2 D: 4 D$ ratios of elite wrestlers were lower compared to non-elite athletes $(p<0.01$, right hand $d=1.70$, left hand $d=1.67)$ and the control group $(p<0.0001$, right hand $d=3.16$, left hand $d=2.00)$. No significant differences were noted among the groups for right - left 2D:4D. We concluded that 2D:4D may discriminate between non-elite and world-class wrestlers. We also suggest that a low 2D:4D ratio could be linked to performance potential in wrestlers. As such, 2D:4D may provide additional information, which is valuable in determining the potential athleticism of an individual, when it is used in conjunction with other measures.
\end{abstract}

Key words: 2D:4D ratio, finger length, prenatal testosterone.

\section{Introduction}

The lengths of the index (2D) and ring (4D) fingers would represent a lot of information in humans. In fact, the $2 \mathrm{D}: 4 \mathrm{D}$ ratio has been studied in different research related to human's physical or even psychological characteristics. For example, males have a lower 2D:4D ratio than females, and this reflects high utero testosterone exposure in their prenatal period (Fink et al., 2006; Manning and Bundred, 2000). Moreover, longitudinal studies have shown that values of 2D:4D are relatively stable with growth (McIntyre et al., 2005; Trivers et al., 2006). However, there is evidence that in females 2D:4D fluctuates due to changes of soft tissues across the menstrual cycle (Mayhew et al., 2007). Extensive studies in humans have found correlations between digit ratios and a variety of physiological and psychological conditions, including fertility, athletic ability, sex-biased diseases, social behaviors, and sexual orientation (Manning et al., 2000; Manning, 2011; Zheng and Cohn, 2011). High fetal androgen levels promote the development of efficient cardiovascular systems, good visuo-spatial abilities, physical endurance, speed and a propensity for aggressive behaviors that may be helpful in sports (Manning and Taylor, 2001). In men, there is a significant negative association between 2D:4D and performance in sports and activities which require speed and endurance, such as rugby (Bennett et al., 2010), running (Manning et al., 2007), skiing (Manning, 2002), soccer (Manning and Taylor,

\footnotetext{
1 - Department of Physical Education, Faculty of Humanities, Tarbiat Modares University, Tehran, Iran.

2 - Department of Exercise Physiology, Sports Medicine Research Center, Sport Sciences Research Institute, Tehran, Iran.

3 - Neuroscience Research Center, Iran University of Medical Sciences, Tehran, Iran.
} 
2001) and gym-based exercises (Hönekopp et al., 2006). However, there is a limited number of studies exploring the value of 2D:4D in determining the potential performance of an individual in power-based sports.

Scientific evidence shows the importance of a low 2D:4D ratio in athletic performance. Manning and Taylor (2001) indicated that feature in professional soccer players (league player in the first team or reserve player, international or non-international player). Further work found that men with a low 2D:4D ratio tended to run faster than men with a high 2D:4D ratio, and that the digit ratio explained up to $25 \%$ of variance in endurance running (Manning et al., 2007). As we mentioned before, there are plenty of reports about the importance of the 2D:4D ratio in speed and endurance based sports, although Manning and Hill (2009) have suggested that 2D:4D is a relatively weak predictor in sports which require strength and power. On the other hand, Longman et al. (2011) reported that a digit ratio was a predictor of ability in male rowers, a sport requiring major energetic contributions from both the aerobic and anaerobic systems. Bennett et al. (2010) found significant relationships between low 2D:4D and performance measures in rugby, and this might suggest that links between 2D:4D and rugby performance are at least in part dependent on power; similar negative correlations between 2D:4D and hand-grip strength in men (but not women) have been reported in Han Chinese (Zhao et al., 2012) and white participants from the USA (Hone and McCullough, 2012). It can therefore be argued that if there is a relationship between low 2D:4D and high performance in strength and power-based sports, it is most likely to be detected by comparing extreme groups on a continuum of sports performance. Studies including both sedentary subjects and objectively assessed elite-status athletes are limited (Bennett et al., 2010; Peeters and Claessens, 2012) and there are no studies concerning the 2D:4D ratio in elite Greco-Roman wrestlers.

Greco-Roman wrestling can only be executed by means of the upper body, with the ultimate goal of pinning the opponent's shoulders to the mat. It demands high levels of power maneuvers that require both absolute whole-body strength and explosiveness, integrating a large isometric component for technical performance (Barbas et al., 2011; Farzad et al., 2011). Recent rule changes in wrestling have made the anaerobic energy metabolism more important than aerobic performance, and this is because of shorting of the match duration and the reduction of the tournament to one day (Cankaya, 2012). Furthermore, it provides short and quick bursts of maximal power during the match (Callan et al., 2000). Yamaner et al. (2010) indicated that GrecoRoman wrestling required significant anaerobic fitness, and operated within a moderate-level of the aerobic system, with the contribution of about 60 and 40\%, respectively. Moreover, combat effectiveness is necessary in wrestling, and it requires proper levels of coordination motor abilities (CMAs). For instance, some researchers have focused on observation of individuals' abilities such as quick reaction (Bujak, 2006) or perceptual skills (Kioumourtzoglou, 1998) in wrestlers. Gierczuk (2008) also showed that the Greco-Roman wrestlers represented a much higher level of motor adaptability and static balance.

To our knowledge, no research, focused on a sample of elite Greco-Roman wrestlers has been accomplished yet. Therefore, the main aim of this study was to compare the $2 \mathrm{D}: 4 \mathrm{D}$ ratio of world-class elite Greco-Roman wrestlers with the 2D:4D ratio of none-elite collegiate wrestlers and sedentary age-matched control males.

\section{Methods}

\section{Participants}

Participants included 10 world-class elite Greco-Roman wrestlers taking part in Olympic fitness camps and were likely to participate in the World Cup in 2013 (almost all of them were medal winners in various international wrestling tournaments such as the Olympic Games (five gold medals), World or Asian championships). Their daily training program before the Olympic games included power training using power cleans in sports conditioning, plyometric training for sport-specific power, muscular endurance training, core strength conditioning, medicine ball exercises, kettlebell training, flexibility exercises and self myofascial release exercises. Twenty nonelite collegiate wrestlers were recruited from different universities of Tehran, Iran; they had wrestling training background of $4.3 \pm 0.9$ years 
and trained for $6.0 \mathrm{~h}$ per week for the last 2 years. The control group consisted of forty male students who were mostly sedentary and did not undertake any physical activities more than once a week. All participants had Iranian ethnic origin. Body mass and standing height of the participants were measured to the nearest $0.05 \mathrm{~kg}$ and $0.1 \mathrm{~cm}$, respectively, using a Martin metal anthropometer and a medical balance scale (A\&D Instruments Ltd., UK). The body mass index (BMI) was calculated as body mass $(\mathrm{kg}) /$ height $\left(\mathrm{m}^{2}\right)$ (Table 1). The study was approved by the Ethical Committee of the School of Medical Sciences of Tarbiat Modares University and was in accordance with the Declaration of Helsinki

\section{Procedures}

Participants were required to place their hands gently on the surface of a scanner (100dpi; HP Scanjet 5590 Digital Flatbed Scanner series, USA) with their digits $2 \mathrm{~cm}$ apart and scanned hand images were then transferred to a PC. Using computer-assisted image analysis (Kinovea 0.8.15 software), the lengths of the left and right second and fourth digits were measured from the midline of the flexion crease, the most proximal to the palm to the fingertip (Figure 1). 2D:4D ratios for the left and right hands were obtained by dividing the measurement of $2 \mathrm{D}$ by $4 \mathrm{D}$. Directional asymmetry in digit ratios was calculated as DR - L = R2D:4D - L2D:4D (Bennett et al., 2010).

\section{Statistical Analyses}

All results are reported as a mean \pm SD. The Kolmogorov-Smirnov test was used to test the normality of the distribution. It showed that the distribution of the variables in our study was not skewed. Therefore, to consider differences between the groups we used parametric tests. To evaluate whether there were significant differences between the three studied groups, analysis of variance (ANOVA) was performed.

When a significant difference was revealed, a Scheffe's post hoc test was used to specify where the difference occurred. We applied the Pearson correlation coefficient test to evaluate the relationship between measures. The alpha level for statistical significance was set at $p \leq 0.05$. All data were analyzed by the SPSS software package (SPSS for Windows; SPSS Inc., Chicago, IL, USA; Version 16.00). Effect sizes were calculated by Cohen'd (d) or Eta2 (n2).

\section{Results}

Results are shown in Table 2. No significant differences were noted among the groups for the right and left second finger length, although significant differences were found in the right $(p=$ $0.035 ; d=0.79)$ and left $(p=0.016 ; d=0.87)$ fourth fingers of elite wrestlers compared with the control group (longer fourth fingers for elite wrestlers). However, there were no significant differences in the right ( $p=0.16 ; d=0.73$ ) and left $(p=0.06 ; d=0.89)$ fourth fingers of elite wrestlers compared to non-elite athletes. The 2D:4D ratios in the right hand of elite wrestlers were lower compared to non-elite athletes $(p=0.004 ; d=1.78)$ and the control group $(p<0.0001 ; d=3.16)$. In addition, the $2 \mathrm{D}: 4 \mathrm{D}$ ratios in the left hand of elite wrestlers were lower compared to non-elite athletes $(p=0.002 ; d=1.66)$ and the control group $(p<0.0001 ; d=2.00)$. No significant differences were noted among the groups for the right - left 2D:4D difference $(p>0.05 ; \quad \mathrm{y} 2=0.034)$. Furthermore, correlations between the 2D:4D ratio and BMI were non-significant in elite and non-elite wrestlers $(p>0.05$; Table 3$)$.

\begin{tabular}{|c|c|c|c|}
\hline \multicolumn{4}{|c|}{$\begin{aligned} \text { Table } 1 \\
\text { Descriptive characteristics of the participants (means } \pm S D)\end{aligned}$} \\
\hline & Elite $(n=10)$ & Non-Elite $(n=20)$ & Control $(n=40)$ \\
\hline Age (yrs) & $25.6 \pm 1.8$ & $22.1 \pm 1.1$ & $24.8 \pm 2.2$ \\
\hline Standing Height $(\mathrm{cm})$ & $178.60 \pm 8.57$ & $180.57 \pm 6.94$ & $176.88 \pm 7.24$ \\
\hline Body Mass (kg) & $81.30 \pm 20.60$ & $75.22 \pm 15.15$ & $74.23 \pm 11.60$ \\
\hline $\begin{array}{l}\text { Body Mass Index } \\
\left(\mathrm{kg} / \mathrm{m}^{2}\right)\end{array}$ & $25.11 \pm 3.98$ & $22.99 \pm 3.88$ & $23.75 \pm 3.71$ \\
\hline
\end{tabular}


Table 2

Mean values of digits among the groups and the results of ANOVA on both hands

\begin{tabular}{lcccc}
\hline & Elite $(\mathrm{n}=10)$ & Non-Elite $(\mathrm{n}=20)$ & Control $(\mathrm{n}=40)$ & $\begin{array}{c}p \text { value for } \\
\text { ANOVA }\end{array}$ \\
\hline Right Second & $7.43 \pm 0.43$ & $7.42 \pm 0.28$ & $7.47 \pm 0.38$ & 0.866 \\
Right Fourth & $7.96 \pm 0.54^{*}$ & $7.65 \pm 0.25$ & $7.57 \pm 0.44$ & 0.035 \\
Right 2D:4D & $0.93 \pm 0.01^{*}$ & $0.97 \pm 0.03+$ & $0.98 \pm 0.02$ & 0.0001 \\
Left Second & $7.44 \pm 0.54$ & $7.44 \pm 0.30$ & $7.51 \pm 0.37$ & 0.758 \\
Left Fourth & $7.97 \pm 0.55^{*}$ & $7.58 \pm 0.28$ & $7.54 \pm 0.42$ & 0.015 \\
Left 2D:4D & $0.93 \pm 0.03^{*}$ & $0.98 \pm 0.03+$ & $0.99 \pm 0.03$ & 0.0001 \\
Right - Left 2D:4D & $-0.0002 \pm 0.022$ & $-0.0116 \pm 0.029$ & $-0.0101 \pm 0.027$ & 0.526 \\
Difference & & & \\
\hline
\end{tabular}

Mean values of digits among the groups and the results of ANOVA on both hands. Values are given as mean $\pm S D$. ${ }^{*}$ Elite compared with Control. t Non-Elite compared with Elite.

\begin{tabular}{|c|c|c|c|}
\hline \multicolumn{4}{|c|}{$\begin{array}{l}\text { Table } 3 \\
\text { Relationships (product-moment correlations) between right, } \\
\text { left 2D:4D and right - left 2D:4D difference and body mass index among the group }\end{array}$} \\
\hline & Elite Wrestlers & Non-Elite Wrestlers & Control Group \\
\hline Right 2D:4D & -0.533 & -0.130 & $0.338^{*}$ \\
\hline Left 2D:4D & -0.089 & -0.132 & 0.228 \\
\hline DR-L & -0.322 & 0.042 & 0.092 \\
\hline \multicolumn{4}{|c|}{${ }^{*}$ Significant $<0.05$ (two-tailed). } \\
\hline
\end{tabular}

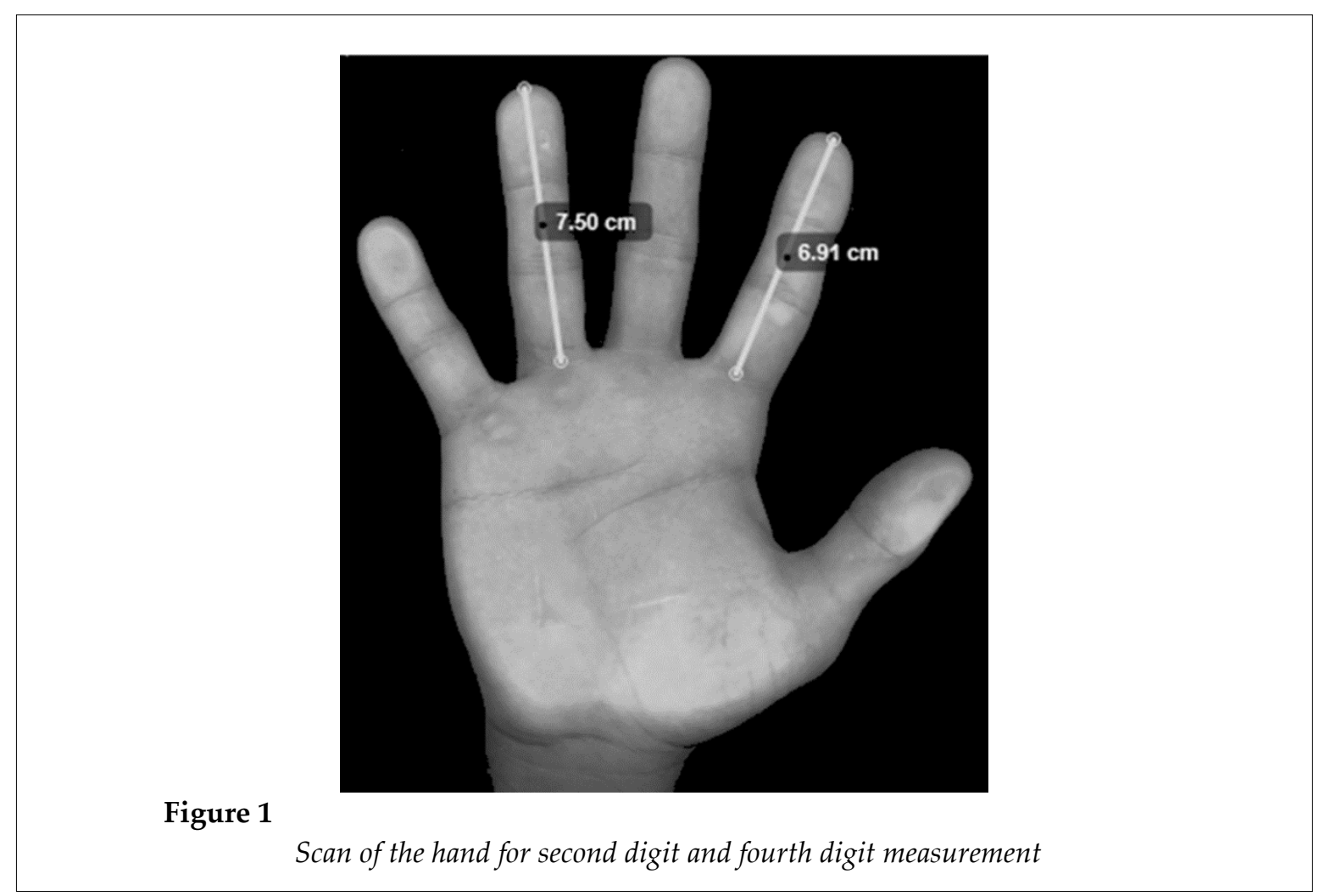




\section{Discussion}

The 2D:4D ratio has been suggested to be a biomarker in determining athletic potential (Manning and Taylor, 2001; Moffit and Swanik, 2011). Although correlational studies have examined the ratio and performance, little research has compared extreme groups on the continuum of sports performance. The present study is the first one to investigate the comparison between 2D:4D in a sample of male wrestlers of world-class level, and non-elite wrestlers and a sample of age-matched sedentary males. There was thus an obvious difference in training motor potential among the groups. Our findings showed that the $2 \mathrm{D}: 4 \mathrm{D}$ ratio in world-class elite wrestlers was different from the $2 \mathrm{D}: 4 \mathrm{D}$ ratio in non-elite athletes and the age-matched control group. Moreover, the effect sizes of the group differences were higher for the right $2 \mathrm{D}: 4 \mathrm{D}$ ratio than for the left one. Right 2D:4D is thought to be more sensitive to prenatal testosterone levels, and often provides a stronger correlate with target traits (Bennett et al., 2010). Thus, the 2D:4D ratio would be considered as a predictor factor in wrestler's performance. Also with regard to stability of 2D:4D values with a growth process (McIntyre et al., 2005; Trivers et al., 2006), age does not play a significant role in this case.

As we mentioned, while low 2D:4D has been shown to correlate with endurance and speed based sports (Manning and Hill, 2009; Hönekopp and Schuster, 2010), it seems that evidence is more mixed for the relationship among 2D:4D, acceleration and strength. Some research reported that as a rather weak predictor (Fink et al., 2006; Zhao et al., 2010), and some did not replicate the same results (Longman et al., 2011). In sumo wrestlers, lower 2D:4D was shown to be linked to higher sumo ranks and better winning records (Tamiya et al., 2012). The significant but weak associations $(\mathrm{r}=-0.174$ to $-0.192 ; \eta 2=0.036$ ) between 2D:4D and the athletic prowess of sumo wrestlers provide further evidence of the possible link between high testosterone levels and muscle strength (Tamiya et al., 2012). Bennett et al. (2010) reported that rugby players had lower 2D:4D than controls for both hands with a large effect size. They asserted that low right 2D:4D and low right - left 2D:4D differences were predictors of high rugby performance. As rugby is a repeated-sprint sport, this might suggest that links between 2D:4D and rugby performance are at least in part dependent on power (Hill et al., 2012). While Manning and Hill (2009) suggested that the widespread relationships between 2D:4D and sports performances may be more related with aerobic efficiency than strength, the results of our study provide some support for a link with measures of power. Enhancing the development of the cardiovascular system by prenatal androgen exposure has been confirmed (Manning and Bundred, 2000). However, regarding this issue, it raises a question if low 2D:4D is a marker of high prenatal testosterone exposure as testosterone has anabolic effects including growth of muscle mass as well as strength and increased power generation, while there is no strong relationship between the digit ratios and strength. The resolution of this question requires further work to measure androgen and estrogen levels in the studied subjects besides the digit ratios and objective performance.

In mouse models, androgen receptor (AR) and estrogen receptor $\alpha(\mathrm{ER}-\alpha)$ activity is higher in foetal digit 4 than in foetal digit 2 . Inactivation of AR reduces growth of digit 4 , which causes a higher 2D:4D ratio, whereas inactivation of ER- $\alpha$ increases growth of digit 4 , which leads to a lower 2D:4D ratio (Zheng and Cohn, 2011). In fact, fourth digit length of the elite wrestlers was significantly greater compared to control group, while there were no significant differences for the second digit among the groups. These results further support the hypothesis that the ratio of androgen to estrogen signaling determines the length of $4 \mathrm{D}$ and, ultimately, affects the 2D:4D ratio.

The right-left 2D:4D difference is a third predictor variable of sports performance in some studies (Bennett et al., 2010; Hill et al., 2012). Hill et al. (2012) demonstrated that low right-left 2D:4D was associated with high maximal oxygen uptake (VO2max), high velocity at VO2max, and high maximum lactate concentration in a sample of teenage boys. They also suggested that low right-left 2D:4D was linked to performance in some sports as it was a proxy of high sensitivity to prenatal testosterone and might also be related to circulating testosterone and high VO2max. However, right-left 2D:4D did not differ among the groups in our study. It has been suggested 
right-left $2 \mathrm{D}: 4 \mathrm{D}$ is a stronger predictor of sports performance than right or left 2D:4D. In rugby players, first-choice players did not differ significantly from second-choice players in their 2D:4D, although they did have a lower right-left 2D:4D difference than second-choice players which is inconsistent with our findings (Bennett et al., 2010).

In conclusion, we found that elite wrestlers had significantly lower right and left hand 2D:4D ratios compared to non-elite wrestlers and sedentary controls. Therefore, the present study could discriminate between nonelite wrestlers and world-class wrestlers by 2D:4D ratios. We should not forget that 2D:4D does not explain all the variance in performance, especially for power-based sport disciplines. However, it seems that if $2 \mathrm{D}: 4 \mathrm{D}$ is used in conjunction with other measures, it may provide additional information, which is valuable in determining the potential athleticism of an individual.

\section{Acknowledgements}

The authors would like to acknowledge all subjects especially national team wrestlers and their coaches, Mohammad Bana and Jamshid Kheirabadi, for their participation in the hard work of this study. Also, we thank Professor JT Manning for reading and commenting on an earlier version of the paper.

\section{References}

Barbas I, Fatouros IG, Douroudos II, Chatzinikolaou A, Michailidis Y, Draganidis D, Jamurtas AZ, Nikolaidis MG, Parotsidis C, Theodorou AA, Katrabasas I, Margonis K, Papassotiriou I, Taxildaris K. Physiological and performance adaptations of elite Greco-Roman wrestlers during a one-day tournament. Eur J Appl Physiol, 2011; 111: 1421-1436

Bennett M, Manning JT, Cook CJ, Kilduff LP. Digit ratio (2D:4D) and performance in elite rugby players. J Sport Sci, 2010; 28: 1415-1421

Bujak Z. Differences in the level of selected elements of motor coordination among taekwon-do contestants at unsophisticated and masterly level. IWFIS, 1998; 23: 233-8

Cankaya C. Examination of young wrestlers' leg reaction times and their relationships with explosive power. World Appl. Sci. J, 2000; 16: 189-97

Callan SD, Brunner DM, Devolve KL, Mulligan SE, Hesson J, Wilber RL, Kearney JT.Physiological profiles of elite freestyle wrestlers. J Strength Cond Res, 2000; 14: 162-169

Farzad B, Gharakhanlou R, Agha-Alinejad H, Curby, DG, Bayati M, Bahraminejad M, Mäestu J. Physiological and performance changes from the addition of a sprint interval program to wrestling training. J Strength Cond Res, 2011; 25: 2392-2399

Fink B, Manning JT, Neave N. The 2nd-4th digit ratio (2D:4D) and neck circumference: implications for risk factors in coronary heart disease. Int J Obesity, 2006; 30: 711-714

Gallup AC, White DD, Gallup GG. Handgrip strength predicts sexual behavior, body morphology, and aggression in male college students. Evol Hum Behav, 2007; 28: 423-429

Gierczuk D. Level of selected indicators of coordination motor Abilities (cma) in greco-roman and freestyle wrestlers Aged 13-14. Pol. J. Sport Tourism, 2008; 15: 192-199

Hill R, Simpson B, Millet G, Manning JT, Kilduff L. Right-left digit ratio (2D:4D) and maximal oxygen uptake. J Sport Sci, 2012; 30: 129-134

Hone LSE, McCullough ME. 2D:4D ratios predict hand grip strength (but not hand grip endurance) in men (but not women). Evol Hum Behav, 2012; 33: 780-789

Hönekopp J, Manning JT, Müller C. Digit ratio (2D:4D) and physical fitness in males and females: Evidence for effects of prenatal androgens on sexually selected traits. Horm Behav, 2006; 49: 545-549

Hönekopp J, Schuster MA. Meta-analysis on 2D:4D and athletic prowess: Substantial relationships but 
neither hand out-predicts the other. Pers Indiv Differ, 2010; 48: 4-10

Kioumourtzoglou E, Kourtessis T, Michalopoulou M, Derri V. Differences in several perceptual abilities between experts and novices in basketball, volleyball and wrestling. Percept Mot Skills, 1998; 86: 899-91

Longman D, Stock JT, Wells JC. Digit ratio (2D:4D) and rowing ergometer performance in males and females. Am J Phys Anthropol, 2011; 144: 337-341

Manning JT, Barley L, Walton J, Lewis-Jones DI, Trivers RL, Singh D, Thornhill R, Rohde P, Bereczkei T, Henzi P, Soler M, Szwed A. The 2nd:4th digit ratio, sexual dimorphism, population differences, and reproductive success. Evidence for sexually antagonistic genes? Evol Hum Behav, 2000; 21: 163-183

Manning JT, Bundred PE. The ratio of 2nd to 4th digit length: a new predictor of disease predisposition? Med Hypotheses, 2000; 54: 855-857

Manning JT, Taylor RP. Second to fourth digit ratio and male ability in sport: implications for sexual selection in humans. Evol Hum Behav, 2001; 22: 61-69

Manning JT. The ratio of 2nd to 4th digit length and performance in skiing. J Sport Med Phys Fit, 2002; fitness: $42,446-450$

Manning JT, Morris L, Caswell N. Endurance running and digit ratio (2D:4D): implications for fetal testosterone effects on running speed and vascular health. Am J Hum Biol, 2007; 19: 416-421

Manning JT, Hill MR. Digit ratio (2D:4D) and sprinting speed in boys. Am J Hum Biol, 2009; 21: 210-213

Manning JT. Resolving the role of prenatal sex steroids in the development of digit ratio. $P$ Natl Acad Sci USA, 2011; 108: 16143-16144

Mayhew TM, Gillam L, McDonald R, Ebling FJ. Human 2D (index) and 4D (ring) digit lengths: their variation and relationships during the menstrual cycle. J Anat, 2007; 211: 630-638

McIntyre MH, Ellison PT, Lieberman DE, Demerath E, Towne B. The development of sex differences in digital formula from infancy in the Fels Longitudinal Study. Proceedings. Biol Control, 2005; 272: 14731479

Moffit DM, Swanik CB. The association between athleticism, prenatal testosterone, and finger length. J Strength Cond Res, 2011; 25: 1085-1088

Peeters MW, Claessens AL. The left hand second to fourth digit ratio (2D:4D) does not discriminate worldclass female gymnasts from age matched sedentary girls. Public Admin Develop, 2012; 7: e40270

Tamiya R, Lee SY, Ohtake F. Second to fourth digit ratio and the sporting success of sumo wrestlers. Evol Hum Behav, 2012; 33: 130-136

Trivers R, Manning JT, Jacobson AA. Longitudinal study of digit ratio (2D:4D) and other finger ratios in Jamaican children. Horm Behav, 2006; 49: 150-156

Yamaner F, Bayraktaroglu T, Atmaca H, Ziyagil MA, Tamer K. Serum leptin, lipoprotein levels and gelucose homeostasis between national wrestlers and sedentary males. Turk. J. Med. Sci, 2010; 40: 471-477

Zhao D, Li B, Yu K, Zheng L. Digit ratio (2D:4D) and handgrip strength in subjects of Han ethnicity: impact of sex and age. Am J Phys Anthropol, 2012; 149: 266-271

Zheng Z, Cohn MJ. Developmental basis of sexually dimorphic digit ratios. P Natl Acad Sci USA, 2011; 108: $16289-16294$

\section{Corresponding author:}

\section{Mohammad Keshavarz}

Department of Physical Education, Faculty of Humanities, Tarbiat Modares University.

Jalal AleAhmad Highway, Nasr Bridge, Tehran, Iran.

Phone number: +98912759 3799

E-mail: m.keshavarz@modares.ac.ir 